Article

\title{
Experimental Manipulation of Psychological Control Scenarios: Implications for Exercise and Memory Research
}

\author{
Jeremiah Blough and Paul D. Loprinzi *(i) \\ Exercise \& Memory Laboratory, Department of Health, Exercise Science and Recreation Management, \\ University of Mississippi, Oxford, MS 386777, USA; jblough@go.olemiss.edu \\ * Correspondence: pdloprin@olemiss.edu
}

Received: 6 April 2019; Accepted: 22 May 2019; Published: 25 May 2019

\begin{abstract}
The purpose of this experiment was to evaluate the extent to which variations in control activities influence memory function, as well as to investigate the participants' memory expectations for the various conditions. A within-subject, counterbalanced experimental design was employed. Across four visits, participants engaged in four tasks, including an acute exercise session, and three cognitive-engagement control tasks of varying degrees of cognitive engagement and valence, namely reading neutral text, looking at a video, and puzzle completion. Participants' perceived expectations for how each condition would improve their memory performance was also assessed. We observed no differences in objective cognitive performance or outcome expectations across the three evaluated control tasks, and thus, future studies may wish to employ either of these control tasks, which should not compromise making comparisons across studies.
\end{abstract}

Keywords: cognition; cognitive function; physical activity; placebo

\section{Introduction}

Recent work within the field of exercise neurophysiology demonstrates beneficial effects of both acute and chronic exercise on human memory. Notably, approximately $48 \%$ to $71 \%$ of the studies on this topic demonstrate favorable effects of exercise on human memory [1,2]. By contrast, approximately half- to one-third of these studies do not demonstrate a memory enhancement effect from exercise. Of course, there are a multitude of factors, ranging from theoretical to methodological, that could account for these mixed findings.

Of central interest to the present experiment is evaluating the extent to which control activities, within an experimental design, influence memory outcomes that are thought to be attributed to exercise. Relatedly, with a mixed-design experimental study (between and within-subject factors), memory outcomes that occur post-exercise are compared to a control group or control scenario (e.g., baseline control, disengagement control, cognitive engagement control, or active control conditions). Non-stable, or non-expected memory scores from a control scenario, can influence whether an interaction (exercise vs. control) effect is observable.

Although research often focuses on the manipulation of various exercise parameters (e.g., intensity, duration, frequency), which is noteworthy, there has been an almost complete neglect for how manipulations and variations of the control activities influence the relationship between exercise and memory function (or cognition in general). This has been emphasized in recent review papers by Pontifex et al. [3] and Boot et al. [4]. Further, as Boot et al. discusses, studies within this field rarely, if ever, evaluate outcome expectations against the control and exercise scenarios, and thus, causal conclusions about any exercise-induced effects may need to be interpreted cautiously, at least 
until appropriately designed studies (including appropriate control groups) are conducted [4]. Stated differently, the lack of equality in expectations for the varying conditions is a serious flaw that could compromise any implications from a study [4].

This topical investigation also aligns with earlier psychological paradigms (e.g., classical conditioning), showing that innovative controls have unveiled much about the sophistication and development of cognitive models [5,6]. As nicely summarized elsewhere, "The take home message: don't look for excuses, add all the control groups you can think of, they may prove even more interesting than the experimental ones (p. 64)" [7].

Couched within the above, and to address these notable gaps in the literature, the primary focus of the present experiment was to evaluate the extent to which variations in control activities (i.e., reading neutral text, looking at a video, and doing a puzzle) influence select cognitive functions, namely memory and planning. Relatedly, in addition to investigating objective cognitive performances across various control activities, we evaluated how the subjective cognitive expectations of that control activity may differ across select control scenarios. As stated, these findings will have important implications on the ability of future studies to make causal inferences regarding the effects of exercise on cognitive function. Regarding the main objective of this study, we hypothesized that there would be no cognitive differences between the control conditions. If an effect is observable, it is conceivable that cognitive outcomes may be influenced by control activities that utilize similar cognitive processes (e.g., the puzzle control task may influence planning-based cognition).

\section{Methods}

\section{Study Design and Participants}

A within-subject randomized controlled intervention was employed. Participants completed four visits in a counterbalanced (via Latin squares) order. Each condition was separated by at least $24 \mathrm{~h}$, and all visits were conducted around the same time of day $( \pm 3 \mathrm{~h})$, except for two visits for one participant. This participant remained in our results, as, when analyzing the data without this participant, the results were similar. Participants engaged in four tasks (one per visit), including an acute exercise session, and three cognitive-engagement control tasks of varying degrees of cognitive engagement and valence, namely reading neutral text, watching a video, and a puzzle (Sudoku) completion. Each of these manipulations occurred prior to memory encoding. This temporal period was chosen because the majority of research investigating the effects of acute exercise on memory function has integrated the exercise manipulation prior to memory encoding [8], and as such, for this experiment, it was important also to integrate the control scenarios at this temporal period.

We specifically evaluated these four conditions for the following reasons. Acute moderate-intensity exercise has been shown to enhance memory function, as well as other cognitive parameters [9-11]. Regarding the three control tasks, these scenarios were chosen because they represent varying degrees of cognitive engagement. For example, Sudoku, which has been used in other experiments [12], may be perceived as a higher-order cognitive engagement task that may prime planning-related cognitive function. Reading a neutral text, which has been used in other experiments [13], induces a neutral valence effect, and may be less cognitively demanding. Lastly, watching a funny video, which has also been utilized in other experiments $[14,15]$, induces a greater valence effect. Notably, there is some evidence to suggest that valence may influence cognitive function [16]. We intentionally did not choose a cognitive disengagement task (e.g., sitting and not interacting with the researcher, or having no access to any stimuli), because of the time period of the control task (i.e., $20 \mathrm{~min}$ ). With a shorter control time period (e.g., $5 \mathrm{~min}$ ), we feel that a cognitive disengagement task would be appropriate, but with a longer time period (e.g., $20 \mathrm{~min}$ ), we feel that it is less appropriate, as it is likely to induce considerable participant boredom and frustration, and ultimately, potential compliance issues with the study.

The visit began with the condition for $20 \mathrm{~min}$ (the exercise visit included a $15 \mathrm{~min}$ bout of treadmill exercise with a 5 min seated rest), followed by the completion of the cognitive tasks (detailed below). 
Twenty-four participants, ages 18-35, were recruited via a non-probability sampling approach (primarily via class announcements and word-of-mouth). This is based on a power analysis, indicating that 24 participants would be needed to achieve adequate statistical power, with inputs of an $\alpha$ error probability of 0.05 , a $1-\beta$ error probability of 0.80 , four within-subject measurements, 0.5 correlation among repeated measures, and an effect size F of 0.25 . This sample size exceeds, or is similar to, other related experiments [9-11,13]. To minimize potential confounding effects on cognition, participants were classified as ineligible if they were a self-reported daily smoker [17,18], pregnant [19], had suffered a concussion within the past 30 days [20], used marijuana or other illegal drugs within $48 \mathrm{~h}$ [21], or were considered a daily alcohol consumer (more than 1 alcoholic drink/day for females and more than 2 alcoholic drinks/day for males) [22]. In addition, participants were instructed to avoid caffeine within $3 \mathrm{~h}$ prior [23] to their visit, and not to exercise within $5 \mathrm{~h}$ before their visit [24]. The study was approved by the university's institutional review board, and all participants provided written consent prior to any data collection.

\section{Measures}

Survey. Given that mood state may influence cognitive function [25], prior to each condition, the participants' mood was assessed with the Positive and Negative Affect Schedule (PANAS) [26], which consists of 20 items on a Likert scale (1, very slightly or not at all; to 5, extremely), with half of the items creating a "positive" mood state, and the other half being a "negative" mood state. To provide behavioral characteristics of the sample, habitual physical activity was assessed via the Physical Activity Vital Signs questionnaire (PAVS) [27-29], which determines weekly minutes engaged in moderate to vigorous physical activity (MVPA).

The participants were also surveyed on their expectations for how each condition would affect their cognitive performance. This consisted of four general statements, with each relating to one of the conditions (i.e., "In general, I think exercising will increase my performance on a memory/cognitive task"; "In general, I think watching a funny video will increase my performance on a memory/cognitive task that is not related to the video"; "In general, I think playing a puzzle game will increase my performance on a memory task that is not related to the puzzle game"; and "In general, I think reading will help increase my performance on a memory/cognitive task that is not related to the material that was read"). The response options were on a 5-point Likert scale, ranging from "Strongly Disagree" (1) to "Strongly Agree" (5). The first visit also included the assessment of demographic and anthropometric data. Also, the use of any medication for the regulation of mood/emotion, and any diagnosis of ADHD/ADD, was recorded.

Exercise. The exercise condition was conducted on a treadmill for 15 minutes at a moderate intensity, that is, $50 \%$ of heart rate reserve (HRR) [30]. The equation used for HRR was: $H R R=\left[\left(\mathrm{HR}_{\max }\right.\right.$ $\left.-\mathrm{HR}_{\text {rest }}\right) \times \%$ intensity] $+\mathrm{HR}_{\text {rest }}$. Heart rate max was defined as: 220 minus age. Participants were monitored periodically throughout the $15 \mathrm{~min}$ bout to ensure their HR was at the target intensity. After completing the exercise bout, participants sat for five minutes before completing the cognitive tasks.

Cognitive Assessments. Three cognitive assessments were evaluated, including a word-list memory task, computer-based episodic memory task (Treasure Hunt Task), and a computer-based planning task (Tower of London). Of interest to our group is the effects of exercise on memory function, and thus, the utilization of several memory function assessments. We also evaluated a planning task, as, in theory, certain control conditions, such as Sudoku, may involve planning-related cognitive demands. The immediate recall aspect of the word-list memory task was always performed first. Following that recall, the THT and Tower of London tasks were completed in random order, and the delayed recall for the word-list was the last task.

The word list was composed of 15 words, for each of the 4 conditions. These words were randomly selected from a list created from the MRC Psycholinguistic Database [31]. This database generated a word list based on a range ( \pm 1 standard deviation of the mean) for each value of familiarity, concreteness, and imageability. The four different word lists (one for each visit) were confirmed to not involve semantically-related words, and the total number of characters were similar for each list. 
For each condition, the participants listened (via audio recording) to the word list twice, with a 5 -second break between lists. Immediately after the second exposure, they verbally recalled as many of the words as they could remember. Later, after completing the two computer tasks (described below), the participants were asked to recall as much of the earlier word list as they could. Previous research demonstrates evidence of a test-retest reliability for related word-list memory tasks [32].

The THT (Treasure Hunt Task) is a computerized task measuring 'what-where-when' episodic memory, and is approximately 10 minutes in duration. Details of the THT have been detailed elsewhere [33,34]. Essentially, this task involved 'hiding' items in various scenes (4 objects per scene), then later indicating what items were hidden, where, and on what occasion. This requires the integration of item, location and temporal memory into a single coherent representation, that is, What-Where-When (WWW) memory. The participants' memory was also assessed for the individual components (what, where and when) without any requirement for integration. Figure 1 displays a schematic of the WWW task. Reliability for these tasks has been previously verified (ICCs >0.7), and it has also demonstrated evidence of convergent validity [34]. The outcome variables assessed included an absolute WWW score (in which the location of the correct object for the correct time is identified exactly). Also, the proportion of correct responses for the separate what, where and when sub-tasks were evaluated. This study used the 'medium' difficulty version of the task, assessing 16 unique item-location-time combinations.

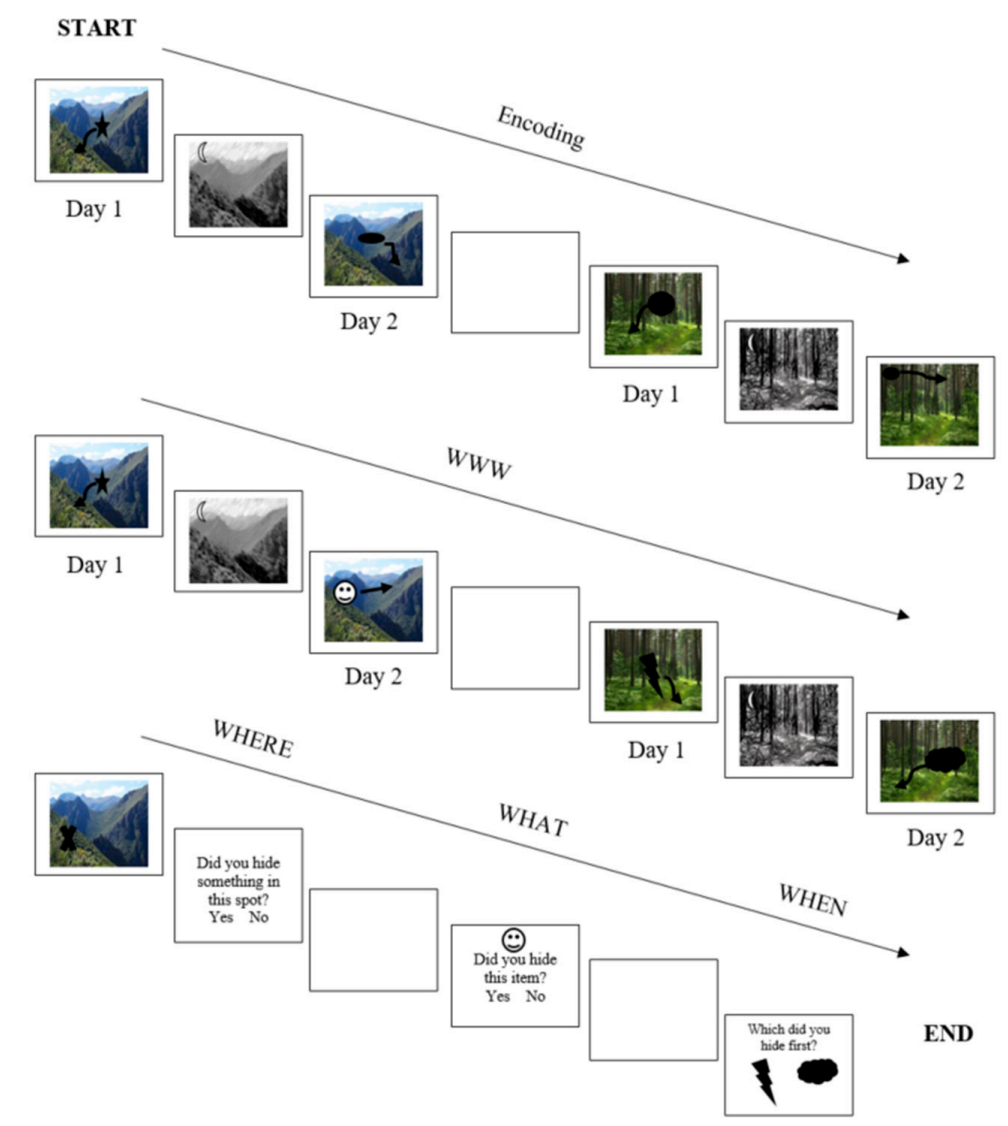

Figure 1. Illustrative example of the episodic memory task or Treasure Hunt Task (THT), employed in our experiment. Items were hidden in two different scenes, across two days labeled as "day 1" and "day 2". Following this encoding portion, participants were then instructed to indicate where they hid each item for both "day 1" and "day 2" and for each scene (What-Where-When (WWW) score). After this, participants completed the "where", "what", and "when" parameters by the recognition and discrimination of the items displayed. 
The Tower of London [35-37] is a computer task that assesses planning-based cognitive functioning. It involves three pegs with three different colored balls on them. Participants were shown a separate window with the three colored balls on three pegs in a different pattern, that is given to them, and then they were asked to rearrange the balls to create the given pattern. Only one ball could be moved at a time with a limited number of moves allowed [38]. Twelve different tasks were employed, and a total score for all trials was calculated as the sum of the scores for each individual task. A higher score is indicative of a better planning-based cognitive performance. This test has been shown to be a valid and reliable assessment of planning-based cognition with good split-half reliability $(r \geq 0.70)$ [39] and 1-week test-retest reliability (ICC, 0.73) [40]. It has demonstrated discriminant-related validity, as planning-based scores from this task have been shown to differ significantly between healthy controls and those with neurological impairment [39].

\section{Statistical Analysis}

All analyses were conducted using JASP (v. 0.9.1.0) statistical software. Both frequentist and Bayesian analyses were computed. For the frequentist analyses, a repeated measures analysis of variance (RM-ANOVA) was conducted for the expectation, affect, THT, and Tower of London data. The immediate and delayed word list recall was analyzed by a two-way RM-ANOVA, with the four visits acting as the first factor, and the immediate and delayed recall as the second factor. If Mauchly's test of sphericity was violated, the Greenhouse-Geisser correction was used. These frequentist analyses were supplemented with Bayesian RM-ANOVA analyses, because Bayesian analyses do not assume large samples, and typically smaller sample sizes can be analyzed without losing power, while retaining precision [41,42]. For the Bayesian RM-ANOVA, Bayes Factors (BF) are reported, with BF greater than 3.0 indicating moderate support for the alternative hypothesis [43]. Thus, the reported Bayes Factors represent the extent to which the alternative hypothesis is supported over the null hypothesis. For the frequentist analyses, statistical significance was set at an a priori alpha of 0.05 . Partial eta-square $\left(\eta^{2} p\right)$ are reported as effect size estimates.

\section{Results}

Table 1 displays the demographic characteristics of the participants. The entire sample $(\mathrm{N}=24)$ had a mean (SD) age of $21.04 \pm 1.12$ years, a mean BMI of $26.58 \pm 6.28 \mathrm{~kg} / \mathrm{m}^{2}$, and a mean level of MVPA of $175.4 \pm 116.8$ minutes/week. The sample was composed of undergraduate students, and $66.7 \%$ were female with $79.2 \%$ of them being non-Hispanic White. Notably, mood was similar across all four visits for both the positive state $\left(\mathrm{F}_{3,23}=0.304, \mathrm{P}=0.822, \eta^{2} \mathrm{p}=0.013, \mathrm{BF}_{10}=0.079\right)$ and the negative state $\left(\mathrm{F}_{2.05,23}=1.362, \mathrm{P}=0.266, \eta^{2} \mathrm{p}=0.056, \mathrm{BF}_{10}=0.256\right)$. Relatedly, mood state at the beginning of each condition was not associated with any of the cognitive outcomes (all $\mathrm{P}^{\prime} \mathrm{s}>0.05$ ). Thus, there was no concern that mood state would be influencing any of the cognitive outcomes across the visits.

Table 2 displays the cognitive outcomes across the four visits. The RM-ANOVA demonstrated that there was evidence that there were no differences between the visits for the WWW $\left(\mathrm{F}_{3,23}=0.989\right.$, $\left.\mathrm{P}=0.403, \eta^{2} \mathrm{p}=0.041, \mathrm{BF}_{10}=0.167\right)$, the What Loop $\left(\mathrm{F}_{3,23}=0.113, \mathrm{P}=0.952, \eta^{2} \mathrm{p}=0.005, \mathrm{BF}_{10}=0.065\right)$, and the Where Loop $\left(\mathrm{F}_{3,23}=0.571, \mathrm{P}=0.636, \eta_{\mathrm{p}}^{2}=0.024, \mathrm{BF}_{10}=0.113\right)$ aspects of the THT, as well as for the Tower of London Task $\left(\mathrm{F}_{3,23}=0.277, \mathrm{P}=0.842, \eta_{\mathrm{p}}^{2}=0.012, \mathrm{BF}_{10}=0.079\right)$. The two-way RM-ANOVA for the word list also demonstrated similar results between the conditions, but there was a significant time effect, as would be expected for comparing immediate recall to delayed recall ( $\mathrm{F}_{\text {(Visit) }}$ $=1.289, \mathrm{P}=0.285, \eta^{2} \mathrm{p}=0.053, \mathrm{~F}_{\text {(Time) }}=125.995, \mathrm{P}<0.001, \eta^{2} \mathrm{p}=0.846, \mathrm{~F}_{\text {(Interaction) }}=1.635, \mathrm{P}=0.189$, $\left.\eta^{2} \mathrm{p}=0.066\right)$. The When Loop of the THT was the only significant variable $\left(\mathrm{F}_{2.39,23}=4.455, \mathrm{P}=0.012\right.$, $\left.\eta^{2}{ }_{p}=0.162, \mathrm{BF}_{10}=7.596\right)$, and for this, neutral text was greater than exercise $(\mathrm{P}=0.012)$, but of central interest to our analyses, none of the control conditions differed, per the post-hoc results (all P's $>0.95$ ). Notably, we recomputed all of these analyses while controlling for the participant's habitual physical activity level (MVPA). For all cognitive outcomes, results were similar when MVPA was included as 
a covariate, and similarly, there were no statistically significant interactions between MVPA and the within-subject cognition factor (all $\mathrm{P}^{\prime} \mathrm{s}>0.05$ ).

Table 1. Participant Characteristics $(\mathrm{N}=24)$.

\begin{tabular}{cc}
\hline Variable & Point Estimate \\
\hline Age (mean years [sd]) & $21.04(1.12)$ \\
Sex (\% female) & 66.7 \\
Race-Ethnicity, $\%$ & \\
Non-Hispanic White $(\mathrm{n}=19)$ & 79.2 \\
Other/Multi-race $(\mathrm{n}=3)$ & 12.5 \\
Non-Hispanic Black (n = 2) & 8.3 \\
Taking Medication to Regulate Mood/Emotion (\% Yes) & 4.2 \\
Currently diagnosed with ADD/ADHD (\% Yes) & 4.2 \\
BMI (mean [sd]) & $26.58(6.28)$ \\
MVPA (mean min per week [sd]) & $175.4(116.8)$
\end{tabular}

Abbreviated terms: BMI—body mass index, MVPA—-moderate to vigorous activity, $\mathrm{n}-$ number of participants, and sd-standard deviation.

Table 2. Cognitive Performance $(\mathrm{N}=24)$.

\begin{tabular}{|c|c|c|c|c|c|}
\hline Variable & $\begin{array}{l}\text { Exercise } \\
\text { Visit }\end{array}$ & $\begin{array}{l}\text { Video } \\
\text { Visit }\end{array}$ & $\begin{array}{l}\text { Sudoku } \\
\text { Visit }\end{array}$ & $\begin{array}{l}\text { Neutral } \\
\text { Text Visit }\end{array}$ & Test Statistic \\
\hline $\begin{array}{l}\text { What-Where-When (WWW) } \\
\text { (mean \% [sd]) }\end{array}$ & $\begin{array}{l}63.28 \\
(21.6)\end{array}$ & $\begin{array}{c}69.53 \\
(21.91)\end{array}$ & $\begin{array}{c}65.63 \\
(23.89)\end{array}$ & $\begin{array}{c}61.2 \\
(22.04)\end{array}$ & $\begin{array}{c}F_{3,23}=0.989, P=0.403 \\
\eta^{2}{ }_{p}=0.041, B_{10}=0.167\end{array}$ \\
\hline $\begin{array}{l}\text { What Loop } \\
\text { (mean \% [sd]) }\end{array}$ & $\begin{array}{l}99.48 \\
(1.77)\end{array}$ & $\begin{array}{c}99.22 \\
(2.8)\end{array}$ & $\begin{array}{l}99.22 \\
(2.11)\end{array}$ & $\begin{array}{l}99.48 \\
(1.77)\end{array}$ & $\begin{array}{c}F_{3,23}=0.113, P=0.952 \\
\eta_{p}^{2}=0.005, B_{10}=0.065\end{array}$ \\
\hline $\begin{array}{l}\text { Where Loop } \\
\text { (mean \% [sd]) }\end{array}$ & $\begin{array}{c}87.03 \\
(10.25)\end{array}$ & $\begin{array}{c}87.24 \\
(15.03)\end{array}$ & $\begin{array}{l}90.89 \\
(9.03)\end{array}$ & $\begin{array}{l}87.24 \\
(13.6)\end{array}$ & $\begin{array}{c}F_{3,23}=0.571, P=0.636 \\
\eta^{2}{ }_{p}=0.024, B_{10}=0.113\end{array}$ \\
\hline $\begin{array}{l}\text { When Loop } \\
\text { (mean \% [sd]) }\end{array}$ & $\begin{array}{c}84.38 \\
(15.09)\end{array}$ & $\begin{array}{l}91.19 \\
(7.87)\end{array}$ & $\begin{array}{c}90.16 \\
(11.49)\end{array}$ & $\begin{array}{l}93.49 \\
(7.01)\end{array}$ & $\begin{array}{c}F_{3,23}=4.455, P=0.006 \\
\eta^{2}{ }_{p}=0.162, B_{10}=7.596\end{array}$ \\
\hline $\begin{array}{l}\text { Tower of London } \\
\text { (mean score }[\mathrm{sd}] \text { ) }\end{array}$ & $\begin{array}{l}33.25 \\
(2.72)\end{array}$ & $\begin{array}{l}33.58 \\
(2.640\end{array}$ & $\begin{array}{l}33.42 \\
(2.28)\end{array}$ & $\begin{array}{c}33.83 \\
(2.3)\end{array}$ & $\begin{array}{c}\mathrm{F}_{3,23}=0.277, \mathrm{P}=0.842 \\
\eta^{2}{ }_{\mathrm{p}}=0.012, \mathrm{BF}_{10}=0.079\end{array}$ \\
\hline $\begin{array}{l}\text { Immediate Recall } \\
\text { (mean score }[\mathrm{sd}] \text { ) }\end{array}$ & $\begin{array}{c}7.54 \\
(2.34)\end{array}$ & $\begin{array}{l}8.49 \\
(2.4)\end{array}$ & $\begin{array}{c}7.67 \\
(2.18)\end{array}$ & $\begin{array}{c}7.58 \\
(2.28)\end{array}$ & $\mathrm{F}_{(\text {Visit })}=1.289, \mathrm{P}=0.285, \eta_{\mathrm{p}}^{2}=0.053$ \\
\hline Delayed Recall & 4.67 & 5.29 & $\begin{array}{c}(2.10) \\
4.42\end{array}$ & $\begin{array}{c}(2.20) \\
5.29\end{array}$ & $\mathrm{~F}_{(\text {Time })}=125.995, \mathrm{P}<0.001, \eta_{\mathrm{p}}^{2}=0.846$ \\
\hline (mean score $[\mathrm{sd}])$ & $(1.93)$ & $(2.9)$ & $(2.83$ & $(2.65)$ & $\mathrm{F}_{(\text {Interaction })}=1.635, \mathrm{P}=0.189, \eta_{\mathrm{p}}^{2}=0.066$ \\
\hline
\end{tabular}

Figure 2 displays the expectation results. Expectations for memory improvements were highest for the exercise visit $(4.08 \pm 0.58)$, when compared to video $(2.63 \pm 0.92)$, Sudoku $(3.29 \pm 0.91)$, and reading $(2.96 \pm 0.96)$. The RM-ANOVA was significant $\left(\mathrm{F}_{3,23}=18.67, \mathrm{P}<0.001, \eta_{\mathrm{p}}^{2}=0.448, \mathrm{BF}_{10}=4.372 \mathrm{e}^{6}\right)$, indicating strong evidence for the alternative hypothesis, and post-hoc results showed that the expectation for exercise was significantly greater than all the other control scenarios (all $\mathrm{P}^{\prime} \mathrm{s}<0.05$ ), but there were no differences for the expectations between the control scenarios (all $\mathrm{P}^{\prime} \mathrm{s} \geq 0.10$ ).

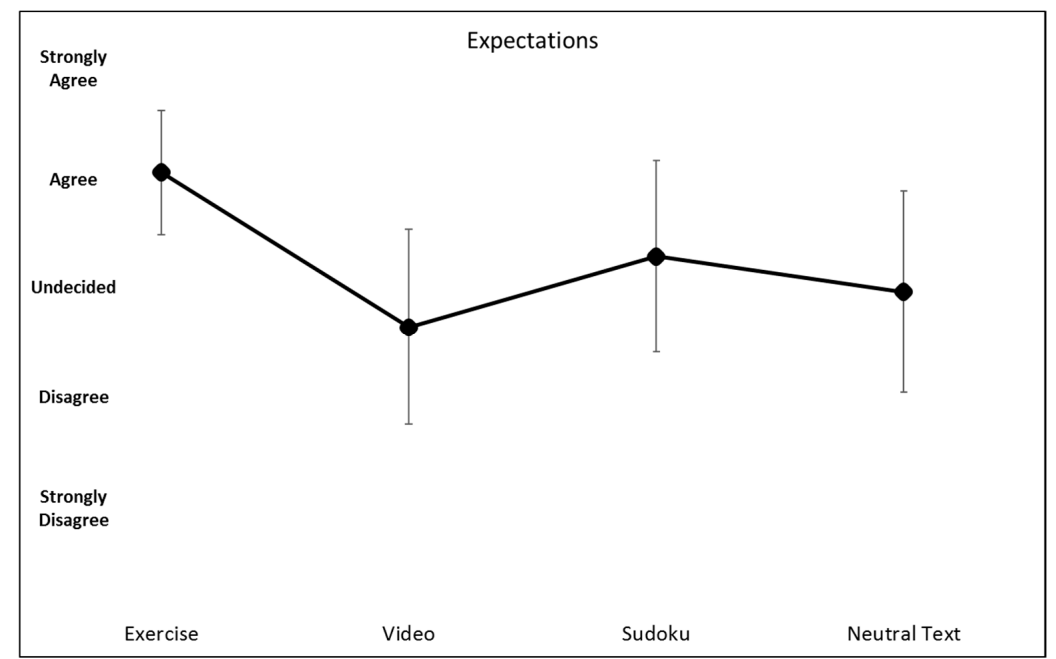

Figure 2. Mean levels of agreement on the perceived benefit of each condition. 


\section{Discussion}

The primary focus of this investigation was to evaluate the extent to which various control activities affect cognitive outcomes, primarily memory function. This examination, particularly in the exercise domain, has yet to be investigated. Our study found that there were no significant differences in any of the cognitive tasks across the control conditions. In addition to examining how these different control activities influenced cognition, we also evaluated how individuals expected their cognitive performance to be improved by each control condition. Inequality in perceived expectations of improvement between an experimental condition and a control condition may cloud any following implications derived from the investigation [4], assuming observed differences also occur in the objective cognitive data. Our results demonstrated a significant difference, in that participants expected to experience greater improvements in their cognitive performance in the exercise condition compared to the other conditions. However, we did not observe any significant differences in perceived expectations between any of the control conditions.

As noted previously, $48 \%$ to $71 \%$ of studies find favorable effects of exercise on memory performance [1,2], which leaves our findings to fall in the approximate half- to one-third that observes null findings. Although speculative, this null exercise-cognitive relationship may be attributed, in part, to the employed exercise intensity level (moderate-intensity exercise). It has been demonstrated that high intensity exercise has a greater benefit for episodic memory tasks than moderate intensity does, due to its propensity to augment catecholamines and neurotrophins that may subserve synaptic plasticity [44]. This exercise-cognitive evaluation, however, was not the central interest of our experiment. Rather, the focal point of this experiment was investigating whether varying the control scenario would have a differential effect on cognitive function. Our collective results demonstrate that the various control activities we employed did not differentially influence any of the cognitive parameters we evaluated.

Although we did not observe a differential cognitive effect from the employed control scenarios, a differential effect is plausible, as, for example, certain control scenarios, such as playing Sudoku, may in fact prime planning-related cognitive processes. Counter to this possibility, we did not observe such an effect. The lack of effect could be because the Sudoku task is not similar enough to the planning-based task (Tower of London) or the memory tasks. That is, it may have produced some neural priming, but not in the correct place, nor to a great enough extent to allow any carry over of that potentiation. An effect was also not observed for the humorous video condition. This is most likely a result of the video's stimulus not being specifically related to the content of the memory task, or it not eliciting an overall neural stimulus great enough to prime cognition. As with the other control conditions, the reading of the neutral text did not cause a significant effect either. While it is possible that some of the words from the word recall list were in the neutral text, the large amount and varying context of the text most likely interfered with any priming that could have taken place if any similarities in the words were present. Like the other control conditions, it is doubtful that reading a neutral text generated any cognitive priming that would affect the cognitive tasks. In light of these findings, future studies can include either of these control types, without the worry of inducing an interaction (exercise vs. control) effect due to using a particular control scenario (as opposed to an interaction effect due to the exercise stimulus). Also, future studies may wish to employ either of these control tasks, which should not compromise making comparisons across studies.

The second aim of our study was to evaluate the participants' perceived expectations on how each control condition would improve cognitive performance. Overall, we did not observe any differential expectations (or cognitive outcomes) across the control conditions. This has important implications for studies employing the types of control activities utilized herein. That is, our evaluated control activities appear to have similar effects on expectations of improvement and actual cognition, and thus, may enhance the comparability of studies utilizing these control scenarios. Our results, however, demonstrated greater participant perceptions of cognitive improvement from an exercise stimulus, despite no differences with the objective cognitive data. Thus, these findings suggest that 
differences in expectations of improvement (i.e., the placebo effect) may not necessarily translate into objective improvements in cognition. As stated in the introduction section, this counters the assertions of others [4], indicating that differences in outcome expectations may undermine the interpretation of objectively-determined cognitive outcomes. Of course, before discounting the possibility that expectations may have a minimal effect on objectively-determined cognitive outcomes, it is important to consider several potential caveats. For example, although our cognitive outcomes have demonstrated evidence of reliability, the utilization of cognitive outcomes that do not have adequate reliability may accentuate a discrepancy between outcome expectations and objective cognitive performance. Another potential explanation for our observed discrepancy is that our outcome expectancy evaluation occurred at the very beginning of the first visit, as opposed to after each visit. This was intentional, because we did not want any of the participants' previous visits to bias their expectations if we assessed expectations prior to each visit. Also, we did not want to draw the participant's attention specifically to their expectations for each visit, thus, we assessed their perceived expectations at the very beginning of the study. Given that there are no established expectation instruments specifically for our study, we developed our own expectation assessment. There is a possibility our assessment of expectation could be improved, since the assessment questions did not explicitly describe the condition, but rather, were more general in their descriptions. In addition, the assessment taking place at the beginning of the study did not take into account any possible alterations in the participants' expectations throughout the study. More research should be conducted on the effect of perceived expectations on memory performance, with future work refining the assessment approach of expectation evaluation. Future work should also attempt to address another point made by Boot et al., by designing experiments where the perceived expectations for improvement are equal for the experimental and control conditions, or with the perceived expectations being even greater for the control group than the experimental group [4].

A limitation of this study is the utilization of a relatively small, homogenous sample, which may limit study generalizability. The strengths of this study are its novelty, experimental design, and implications for future work on this topic. As discussed above, additional work on this novel paradigm is needed, which includes, for example, refinement of the outcome expectations assessment, examining the temporal effects of control activities (e.g., before and after the cognitive task), and investigating additional control activities on cognition. Regarding the latter, it would be useful to identify which control activities have no effect upon cognition, which have a priming effect on cognition, and which have a differential effect on cognition when compared to acute exercise. As stated in the methods section, we intentionally did not employ a cognitive disengagement control because of the time period (i.e., $20 \mathrm{~min}$ ), but for future studies that are evaluating the effects of very short bouts of exercise (e.g., 5 min of walking [45] or high-intensity interval training), this cognitive disengagement control may be more appropriate to evaluate. As we have thoroughly discussed elsewhere [46,47], one of the postulated mechanisms through which exercise may influence memory function is via exercise-induced increases in long-term potentiation, or sustained neuronal excitability. Hippocampal long-term potentiation from acute exercise is thought to occur through several pathways, including activation of the muscle stretch receptors and the vagus nerve. Thus, future work that has an interest in evaluating the effects of different exercise intensities, which may differentially activate the muscle stretch receptors (and the vagus nerve), may wish to include an active control task (e.g., passive stretching). All the conditions for this study occurred prior to the cognitive tasks. Future work will, and has started to, evaluate the effects of exercise at different temporal periods (e.g., before memory encoding and during memory consolidation) $[10,11,24,48,49]$. Therefore, future work should also evaluate the effect of control activities at these different temporal periods. For example, if a study has participants exercising during the memory consolidation phase, the control activity will need to be temporally matched during this consolidation phase. If the employed control task is a more cognitively demanding task, like Sudoku, it may, possibly, induce a retroactive memory interference effect during the consolidation phase. Alternatively, the content of Sudoku may not be similar enough to the memory task to elicit any interference, but another control activity, like a video, may have more 
similar content, and in turn, could induce an interference effect. Thus, future work should investigate whether or not control tasks, at varying temporal periods, have any beneficial or detrimental effects on cognitive performance.

We view our present experiment as a good starting point in highlighting that the control tasks may be just as important as the exercise stimulus when designing experimental studies on exercise and cognition. This relatively unexplored paradigm in this domain underscores the importance of additional experimental work on this topic. As stated, such work should consider evaluating other control tasks (e.g., cognitive disengagement, active control), and investigating how the control tasks influence memory function when implemented during different temporal periods of the memory phase (e.g., before encoding or during memory consolidation). Lastly, when appropriate (i.e., based on the cognitive assessment), future work on this paradigm (i.e., varying the control tasks) should consider implementing a baseline control task. In our experiment, we intentionally chose not to implement a baseline control because it likely would induce a proactive memory interference effect for the word-list memory task. For example, if we implemented two different word lists in the same visit, with one list occurring prior to the control task and the other occurring after the control task, the first list may induce a proactive memory interference effect (i.e., recall of the second word list may be confounded by previous retention of words from the first list).

In conclusion, our novel investigation evaluated whether there was a differential effect of acute moderate-intensity exercise and various control activities on objectively-determined cognitive function and perceived expectations of the cognitive task. We did not observe a beneficial effect of acute moderate-intensity exercise on cognition. However, being a central focus of the present experiment, we also did not observe any differential effects of varying control tasks (e.g., reading neutral text, watching a video, or a cognitively demanding puzzle) on objectively-determined cognitive performance.

Our outcome expectation results demonstrated that, despite no observed differences on objective cognitive performance, participants expected the acute exercise stimulus (vs. the control tasks) to have a more beneficial effect upon cognition. This discrepancy between objective cognition performance and outcome expectation provides suggestive evidence that a placebo effect (expectations) may be less applicable in the exercise-cognition domain. Lastly, we observed no differences in objective cognitive performance or outcome expectations across our three evaluated control tasks, which suggests that, if our findings are replicated, future studies may wish to employ either of these control tasks. That is, across-study comparisons may not be compromised when utilizing these different control tasks, and similarly, for within- or between-subject designs that involve multiple control periods during the experiment, it may be acceptable to employ any one, or all of these, evaluated control tasks.

Author Contributions: J.B. and P.D.L. were involved in conceptualizing the study, statistical analyses, and manuscript writing. J.B. collected the data.

Funding: This research received no external funding.

Conflicts of Interest: The authors declare no conflict of interest.

\section{References}

1. Roig, M.; Nordbrandt, S.; Geertsen, S.S.; Nielsen, J.B. The effects of cardiovascular exercise on human memory: A review with meta-analysis. Neurosci. Biobehav. Rev. 2013, 37, 1645-1666. [CrossRef]

2. Loprinzi, P.D.; Frith, E.; Edwards, M.K.; Sng, E.; Ashpole, N. The effects of exercise on memory function among young to middle-aged adults: Systematic review and recommendations for future research. Am. J. Health Promot. 2018, 32, 691-704. [CrossRef] [PubMed]

3. Pontifex, M.B.; McGowan, A.L.; Chandler, M.C.; Gwizdala, K.L.; Parks, A.C.; Fenn, K.; Kamijo, K. A primer on investigating the after effects of acute bouts of physical activity on cognition. Psychol. Sport Exerc. 2018, 40, 1-22. [CrossRef]

4. Boot, W.R.; Simons, D.J.; Stothart, C.; Stutts, C. The pervasive problem with placebos in psychology: Why active control groups are not sufficient to rule out placebo effects. Perspect. Psychol. Sci. 2013, 8, 445-454. [CrossRef] [PubMed] 
5. Kremer, E.F. The truly random control procedure: Conditioning to the static cues. J. Comp. Physiol. Psychol. 1974, 86, 700. [CrossRef] [PubMed]

6. Kremer, E.F. Truly random and traditional control procedures in CER conditioning in the rat. J. Comp. Physiol. Psychol. 1971, 76, 441. [CrossRef]

7. Dudai, Y. Memory from A to Z: Keywords, Concepts, and Beyond; Oxford University Press: New York, NY, USA, 2004.

8. Loprinzi, P.D.; Blough, J.; Crawford, L.; Ryu, S.; Zou, L.; Li, H. The temporal effects of acute exercise on episodic memory function: Systematic review with meta-analysis. Brain Sci. 2019, 9, 87. [CrossRef] [PubMed]

9. Crush, E.A.; Loprinzi, P.D. Dose-response effects of exercise duration and recovery on cognitive functioning. Percept. Mot. Ski. 2017, 124, 1164-1193. [CrossRef]

10. Siddiqui, A.; Loprinzi, P. Experimental Investigation of the Time Course Effects of Acute Exercise on False Episodic Memory. J. Clin. Med. 2018, 7, 157. [CrossRef] [PubMed]

11. Sng, E.; Frith, E.; Loprinzi, P.D. Temporal effects of acute walking exercise on learning and memory function. Am. J. Health Promot. 2018, 32, 1518-1525. [CrossRef] [PubMed]

12. McNerney, M.W.; Radvansky, G.A. Mind racing: The influence of exercise on long-term memory consolidation. Memory 2015, 23, 1140-1151. [CrossRef] [PubMed]

13. Labban, J.D.; Etnier, J.L. The Effect of Acute Exercise on Encoding and Consolidation of Long-Term Memory. J. Sport Exerc. Psychol. 2018, 40, 336-342. [CrossRef] [PubMed]

14. Liu, D.L.J.; Graham, S.; Zorawski, M. Enhanced selective memory consolidation following post-learning pleasant and aversive arousal. Neurobiol. Learn. Mem. 2008, 89, 36-46. [CrossRef]

15. Wingate, S.; Crawford, L.; Frith, E.; Loprinzi, P.D. Experimental investigation of the effects of acute exercise on memory interference. Health Promot. Perspect. 2018, 8, 208. [CrossRef] [PubMed]

16. Bergmann, H.C.; Rijpkema, M.; Fernandez, G.; Kessels, R.P. The effects of valence and arousal on associative working memory and long-term memory. PLoS ONE 2012, 7, e52616. [CrossRef]

17. Jubelt, L.E.; Barr, R.S.; Goff, D.C.; Logvinenko, T.; Weiss, A.P.; Evins, A.E. Effects of transdermal nicotine on episodic memory in non-smokers with and without schizophrenia. Psychopharmacology 2008, 199, 89-98. [CrossRef]

18. Klaming, R.; Annese, J.; Veltman, D.J.; Comijs, H.C. Episodic memory function is affected by lifestyle factors: A 14-year follow-up study in an elderly population. Aging Neuropsychol. Cognit. 2017, 24, 528-542. [CrossRef]

19. Henry, J.D.; Rendell, P.G. A review of the impact of pregnancy on memory function. J. Clin. Exp. Neuropsychol. 2007, 29, 793-803. [CrossRef] [PubMed]

20. Wammes, J.D.; Good, T.J.; Fernandes, M.A. Autobiographical and episodic memory deficits in mild traumatic brain injury. Brain Cognit. 2017, 111, 112-126. [CrossRef] [PubMed]

21. Hindocha, C.; Freeman, T.; Xia, J.; Shaban, N.; Curran, H. Acute memory and psychotomimetic effects of cannabis and tobacco both 'joint' and individually: A placebo-controlled trial. Psychol. Med. 2017, 47, 2708-2719. [CrossRef] [PubMed]

22. Le Berre, A.P.; Fama, R.; Sullivan, E.V. Executive functions, memory, and social cognitive deficits and recovery in chronic alcoholism: A critical review to inform future research. Alcohol. Clin. Exp. Res. 2017, 41, 1432-1443. [CrossRef] [PubMed]

23. Sherman, S.M.; Buckley, T.P.; Baena, E.; Ryan, L. Caffeine enhances memory performance in young adults during their non-optimal time of day. Front. Psychol. 2016, 7, 1764. [CrossRef] [PubMed]

24. Labban, J.D.; Etnier, J.L. Effects of acute exercise on long-term memory. Res. Q. Exerc. Sport 2011, 82, 712-721. [CrossRef]

25. Singer, J.A.; Salovey, P. Mood and memory: Evaluating the network theory of affect. Clin. Psychol. Rev. 1988, 8, 211-251. [CrossRef]

26. Watson, D.; Clark, L.A.; Tellegen, A. Development and validation of brief measures of positive and negative affect: The PANAS scales. J. Personal. Soc. Psychol. 1988, 54, 1063. [CrossRef]

27. Ball, T.J.; Joy, E.A.; Gren, L.H.; Cunningham, R.; Shaw, J.M. Predictive validity of an adult physical activity "Vital Sign" recorded in electronic health records. J. Phys. Act. Health 2016, 13, 403-408. [CrossRef] [PubMed]

28. Ball, T.J.; Joy, E.A.; Gren, L.H.; Shaw, J.M. Peer Reviewed: Concurrent Validity of a Self-Reported Physical Activity "Vital Sign" Questionnaire With Adult Primary Care Patients. Prev. Chronic Dis. 2016, 13, E16. [CrossRef] [PubMed] 
29. Ball, T.J.; Joy, E.A.; Goh, T.L.; Hannon, J.C.; Gren, L.H.; Shaw, J.M. Validity of two brief primary care physical activity questionnaires with accelerometry in clinic staff. Prim. Health Care Res. Dev. 2015, 16, 100-108. [CrossRef]

30. Garber, C.E.; Blissmer, B.; Deschenes, M.R.; Franklin, B.A.; Lamonte, M.J.; Lee, I.M.; Nieman, D.C.; Swain, D.P. Quantity and quality of exercise for developing and maintaining cardiorespiratory, musculoskeletal, and neuromotor fitness in apparently healthy adults: Guidance for prescribing exercise. Med. Sci. Sports Exerc. 2011, 43, 1334-1359. [CrossRef]

31. Wilson, M. MRC psycholinguistic database: Machine-usable dictionary, version 2.00. Behav. Res. Methods Instrum. Comput. 1988, 20, 6-10. [CrossRef]

32. Geffen, G.M.; Butterworth, P.; Geffen, L.B. Test-retest reliability of a new form of the auditory verbal learning test (AVLT). Arch. Clin. Neuropsychol. 1994, 9, 303-316. [CrossRef] [PubMed]

33. Cheke, L.G. What-where-when memory and encoding strategies in healthy aging. Learn. Mem. 2016, 23, 121-126. [CrossRef] [PubMed]

34. Cheke, L.G.; Simons, J.S.; Clayton, N.S. Higher body mass index is associated with episodic memory deficits in young adults. Q. J. Exp. Psychol. 2016, 69, 2305-2316. [CrossRef] [PubMed]

35. Krikorian, R.; Bartok, J.; Gay, N. Tower of London procedure: A standard method and developmental data. J. Clin. Exp. Neuropsychol. 1994, 16, 840-850. [CrossRef]

36. Schnirman, G.M.; Welsh, M.C.; Retzlaff, P.D. Development of the Tower of London-revised. Assessment 1998, 5, 355-360. [CrossRef] [PubMed]

37. Shallice, T. Specific impairments of planning. Philos. Trans. R. Soc. Lond. Ser. B Biol. Sci. 1982, 298, 199-209. [CrossRef]

38. Bull, R.; Espy, K.A.; Senn, T.E. A comparison of performance on the Towers of London and Hanoi in young children. J. Child Psychol. Psychiatry 2004, 45, 743-754. [CrossRef]

39. Köstering, L.; Schmidt, C.S.; Egger, K.; Amtage, F.; Peter, J.; Klöppel, S.; Beume, L.A.; Hoeren, M.; Weiller, C.; Kaller, C.P. Assessment of planning performance in clinical samples: Reliability and validity of the Tower of London task (TOL-F). Neuropsychologia 2015, 75, 646-655. [CrossRef]

40. Köstering, L.; Nitschke, K.; Schumacher, F.K.; Weiller, C.; Kaller, C.P. Test-retest reliability of the Tower of London Planning Task (TOL-F). Psychol. Assess. 2015, 27, 925. [CrossRef]

41. Lee, S.-Y.; Song, X.-Y. Evaluation of the Bayesian and maximum likelihood approaches in analyzing structural equation models with small sample sizes. Multivar. Behav. Res. 2004, 39, 653-686. [CrossRef]

42. Hox, J.J.; van de Schoot, R.; Matthijsse, S. How few countries will do? Comparative survey analysis from a Bayesian perspective. Surv. Res. Methods 2012, 6, 87-93.

43. Jarosz, A.F.; Wiley, J. What are the odds? A practical guide to computing and reporting Bayes factors. J. Probl. Solving 2014, 7, 2. [CrossRef]

44. Loprinzi, P.D. Intensity-specific effects of acute exercise on human memory function: Considerations for the timing of exercise and the type of memory. Health Promot. Perspect. 2018, 8, 255. [CrossRef]

45. Jaffery, A.; Edwards, M.K.; Loprinzi, P.D. The effects of acute exercise on cognitive function: Solomon experimental design. J. Prim. Prev. 2018, 39, 37-46. [CrossRef] [PubMed]

46. Loprinzi, P.; Ponce, P.; Frith, E. Hypothesized mechanisms through which acute exercise influences episodic memory. Physiol. Int. 2018, 105, 285-297. [CrossRef]

47. Loprinzi, P.D.; Edwards, M.K.; Frith, E. Potential avenues for exercise to activate episodic memory-related pathways: A narrative review. Eur. J. Neurosci. 2017, 46, 2067-2077. [CrossRef]

48. Haynes, J.T., IV; Frith, E.; Sng, E.; Loprinzi, P.D. Experimental effects of acute exercise on episodic memory function: Considerations for the timing of exercise. Psychol. Rep. 2018, 0033294118786688.

49. Frith, E.; Sng, E.; Loprinzi, P.D. Randomized controlled trial evaluating the temporal effects of high-intensity exercise on learning, short-term and long-term memory, and prospective memory. Eur. J. Neurosci. 2017, 46, 2557-2564. [CrossRef] [PubMed]

(C) 2019 by the authors. Licensee MDPI, Basel, Switzerland. This article is an open access article distributed under the terms and conditions of the Creative Commons Attribution (CC BY) license (http://creativecommons.org/licenses/by/4.0/). 